\title{
Hydrogen bond simulation in molecular crystals of tyrosine
}

\author{
(C) Tatiana G. Volkova, ${ }^{1} *$ Irina O. Talanova ${ }^{2+}$ \\ ${ }^{1}$ Department of Organic and Physical Chemistry. Ivanovo State University. \\ Ermak St., 39. Ivanovo, 153025. Russia.E-mail:tgvolkova@yandex.ru \\ ${ }^{2}$ Department of Biochemistry. Ivanovo State Medical Academy. \\ Sheremetevsky pr.,8.Ivanovo, 153012.Russia.E-mail: i75@list.ru
}

*Supervising author; ${ }^{+}$Corresponding author Keywords: amino acids, tyrosine, $\alpha$-amino- $\beta$-paraoxyphenylpropionic acid, hydrogen bond, intermolecular interaction, simulation.

\begin{abstract}
The problem of the study of hydrogen bonds in biomolecules and living systems is important. Among the drugs, doctors emphasize substances of natural origin involved in metabolic processes. Such compounds include amino acids, peptides, vitamins, enzymes, macro- and microelements, and other biologically active substances, many of which are capable of forming hydrogen bonds. Amino acids and their derivatives are drugs of metabolic pharmacotherapy, characterized by low toxicity and severity of side effects. They also have virtually no allergenic effect, which makes them promising for the creation of drugs or their modifications. The instability of the hydrogen bond can significantly affect the state of pharmaceutical drug containing, for example, amino acids, during their storage, transportation or technological processing. One of the methods for studying the nature and determining the strength of hydrogen bonds is quantum chemical simulation. The calculation of the interaction energy in the studied molecular associate and its decomposition have been carried out according to Morocuma's method (HF/6-31G (PC GAMESS). The evaluation of such energy components as electrostatic, exchange repulsion, polarization, charge transfer, mixing is given. The main contribution to the interaction energy comes from the electrostatic component. All the studied models have the same distribution of the components of the interaction energy in order of magnitude. Significant difference in the interaction energy in two model systems was noted, that could be explained by different geometry of hydrogen bonds. The comparison of received data made it possible to conclude that there are three types of hydrogen bonds in the molecular tyrosine crystal, which differ from each other in energy and geometry.
\end{abstract}

\section{References}

[1] E. Arunan, G.R. Desiraju, R.A. Klein, J. Sadlej, S. Scheiner, I. Alkorta, D.C. Clary, R.H. Crabtree, J.J. Dannenberg, P. Hobza, H.G. Kjaergaard, A.C. Legon, B. Mennucci, D.J. Nesbitt. Defining the hydrogen bond: An account (IUPAC Technical Report). Pure Appl. Chem. 2011. Vol.83. No.8. P.1619-1636.

[2] E.V. Boldyreva, T.N. Drebushchak, E.S. Shutova. Structural distortion of the $\alpha, \beta$ - and $\gamma$-polymorphs of glycine on cooling. Z. Kristallogr. 2003. Vol.218. No.5. P.366-376.

[3] G.L. Perlovich, L.K. Hansen, A. Bauer-Brandl. The Polymorphism of Glycine. Thermochemical and structural aspects. J. Therm. Anal. Calorim. 2001. Vol.66. No.3. P.699-715.

[4] E.A. Losev, M.A. Mikhailenko, E.V. Boldyreva. Effect of $\alpha$ - and $\gamma$-polymorphs of glycine on the intranasal delivery of manganese hydroxide nanoparticles into brain structures. Doklady Physical Chemistry. 2011. Vol.439. No.2. P.153-156.

[5] R.L. Baldwin. In Search of the Energetic Role of Peptide Hydrogen Bonds. Journal of Biological Chemistry. 2003. Vol.278. No.20. P.17581-17588.

[6] T.G. Volkova, I.O. Talanova, A.A. Lysenok. Evaluation of interaction energy in aliphatic amino acids. Abstracts of the cluster of conferences 2018: XIII International conference «Problems of solvation and complexation in solutions», X International conference «Kinetics and crystallization mechanism», international Symposium «Smart materials», Summer school-conference of young scientists «Modeling of smart materials». 2018. P.377. (russian)

[7] Cambridge Crystallographic Date Centre (CCDC): http://www.ccdc.com.ac.uk.

[8] A.A. Granovsky. PCGAMESS version 7.1. http://classic.chem.msu.su/gran/gamess/index.html.

[9] K. Morokuma, K. Kitaura. A new energy decomposition scheme for molecular interactions within the Hartree-Fock approximation. International Journal of Quantum Chemistry. 1976. Vol.X. P.325-327.

Kazan. The Republic of Tatarstan. Russia. (c) Butlerov Communications. 2019. Vol.58. No.6. 
[10] A.A. Lysenok, P.A. Kalmykov, N.I. Giricheva, T.G. Volkova, and E.G. Belkina. Quantum-chemical modeling of hydrogen bonds in $\alpha$-glycine. Butlerov Communications. 2019. Vol.57. No.1. P.21-26. DOI: $10.37952 /$ ROI-jbc-01/19-57-1-21 